\title{
Erratum to: 5th National Congress of the Italian Society of Colorectal Surgery: From Personal Opinions to Evidence-Based Surgery
}

Carlo V Castle, Lecce, Italy, 7-9 October 2013

Published online: 19 December 2013

(C) Springer-Verlag Italia 2013

Erratum to: Tech Coloproctol

DOI 10.1007/s10151-013-1096-6

The name of the fourth author of the abstract entitled "Biological anal fistula plug: preliminary results" was rendered incorrectly; the correct name is E. Gentile Warschauer. 